\title{
The complete mitochondrial genome of an agamid lizard from the Afro-Asian subfamily agaminae and the phylogenetic position of Bufoniceps and Xenagama
}

\author{
J. Robert Macey ${ }^{\mathrm{a}, *}$, James A. Schulte II ${ }^{\mathrm{b}}$, Jonathan J. Fong ${ }^{\mathrm{a}}$, Indraneil Das ${ }^{\mathrm{c}}$, \\ Theodore J. Papenfuss ${ }^{\text {a }}$ \\ ${ }^{a}$ Museum of Vertebrate Zoology, 3101 Valley Life Science Building, University of California, Berkeley, CA 94720, USA \\ ${ }^{\mathrm{b}}$ Department of Biology, 177 Clarkson Science Center, MRC 5805, 8 Clarkson Avenue, Clarkson University, Potsdam, NY 13699-5805, USA \\ ${ }^{\mathrm{c}}$ Institute of Biodiversity and Environmental Conservation, Universiti Malaysia Sarawak, 94300, Kota Samarahan, Sarawak, Malaysia
}

Received 21 July 2005; revised 21 August 2005; accepted 30 August 2005

\section{Introduction}

Squamate reptiles are traditionally divided into six groups: Iguania, Anguimorpha, Scincomorpha, Gekkota (these four are lizards), Serpentes (snakes), and Amphisbaenia (the so-called worm lizards). The Iguania is recognized as having two major lineages the Iguanidae and Acrodonta (Agamidae and Chamaeleonidae). Currently, there are complete mitochondrial genomes from three Anguimorpha (Kumazawa, 2004; Kumazawa and Endo, 2004), two from the Scincomorpha (Kumazawa, 2004; Kumazawa and Nishida, 1999), one from Gekkota (Macey et al., 2005) two from Serpentes (Kumazawa, 2004; Kumazawa et al., 1998) and 12 from Amphisbaenia (Macey et al., 2004). In addition, two representatives of the Iguanian family Iguanidae (Janke et al., 2001; Kumazawa, 2004) have been sequenced. Its' sister taxon, the Acrodonta, consists of seven monophyletic groups-the family Chamaeleonidae and six distantly related subfamilies of the family Agamidae (Macey et al., 2000 b). Currently, the only acrodont lineage sequenced for the complete mitochondrial genome is Pogona vitticeps from the Australasian agamid subfamily Amphibolurinae (Amer and Kumazawa, 2005a).

Here, we report the complete mitochondrial genome of Xenagama taylori, a North African representative of the agamid subfamily Agaminae and compare it to $P$. vitticepes. The agamid lizard genus Xenagama is distributed in a

\footnotetext{
${ }^{*}$ Corresponding author. Fax: +15106438238.

E-mail address: jrobertmacey@yahoo.com (J.R. Macey).
}

restricted region of the Horn of Africa in northwestern Somalia and adjacent eastern Ethiopia as shown in Fig. 1, with two species currently recognized (Moody, 1980; Wermuth, 1967). In addition, we report a segment of the mitochondrial genome of Bufoniceps laungwalansis spanning from nadl to coxl. The monotypic genus Bufoniceps is restricted to the Thar Desert, Jaisalmer District, Rajasthan State, India and adjacent Pakistan (Fig. 1).

Both Bufoniceps and Xenagama belong to the subfamily Agaminae and are poorly understood phylogenetically. These genera were not represented in the most recent molecular systematic study of the Agamidae (Macey et al., 2000b). Bufoniceps was originally described as a member of the West Asian genus Phrynocephalus (Sharma, 1978), and later placed in its' own genus (Arnold, 1992) because morphological data suggested it is the sister taxon to Phrynocephalus (Arnold, 1999). Xenagama was previously considered part of the Agama complex before the allocation of its member species to several genera (see, Moody, 1980).

\section{Materials and methods}

\subsection{Specimen information}

The sample of Bufoniceps laungwalansis from which DNA was extracted is deposited in the Raffles Museum of Biodiversity Research, National University of Singapore as ZRC 2.5681. The collection locality of this specimen is elevation $192 \mathrm{~m}, 26.50 .26^{\prime} \mathrm{N} 70.32 .24^{\prime} \mathrm{E}$, vicinity of Sam, Rajasthan State, India. The mitochondrial segment spanning 